\title{
The Evolution of Stop-motion Animation Technique Through 120 Years of Technological Innovations
}

\author{
Vincenzo Maselli \\ Department of Planning, Design and Technology of Architecture, "Sapienza" University, Rome, Italy \\ Email address: \\ vincenzo.maselli@uniroma1.it

\section{To cite this article:} \\ Vincenzo Maselli. The Evolution of Stop-motion Animation Technique Through 120 Years of Technological Innovations. International \\ Journal of Literature and Arts. Vol. 6, No. 3, 2018, pp. 54-62. doi: 10.11648/j.ijla.20180603.12
}

Received: June 20, 2018; Accepted: July 17, 2018; Published: August 18, 2018

\begin{abstract}
Stop-motion animation history has been put on paper by several scholars and practitioners who tried to organize 120 years of technological innovations and material experiments dealing with a huge literature. Bruce Holman (1975), Neil Pettigrew (1999), Ken Priebe (2010), Stefano Bessoni (2014), and more recently Adrián Encinas Salamanca (2017), provided the most detailed even tough partial attempts of systematization, and designed historical reconstructions by considering specific periods of time, film lengths or the use of stop-motion as special effect rather than an animation technique. This article provides another partial historical reconstruction of the evolution of stop-motion and outlines the main events that occurred in the development of this technique, following criteria based on the innovations in the technology of materials and manufacturing processes that have influenced the fabrication of puppets until the present day. The systematization follows a chronological order and takes into account events that changed the technique of a puppets' manufacturing process as a consequence of the use of either new fabrication processes or materials. Starting from the accident that made the French film-pioneer Georges Méliès discover the trick of the replacement technique at the end of the nineteenth century, the reconstruction goes through 120 years of experiments and films. "Build up" puppets fabricated by the Russian puppet animator Ladislaw Starevicz with insect exoskeletons, the use of clay puppets and the innovations introduced by LAIKA entertainment in the last decade such as Stereoscopic photography and the $3 \mathrm{D}$ computer printed replacement pieces, and then the increasing influence of digital technologies in the process of puppet fabrication are some of the main considered events. Technology transfers, new materials' features, innovations in the way of animating puppets, are the main aspects through which this historical analysis approaches the previously mentioned events. This short analysis is supposed to remind and demonstrate that stop-motion animation is an interdisciplinary occasion of both artistic expression and technological experimentation, and that its evolution and aesthetic is related to cultural, geographical and technological issues. Lastly, if the technology of materials and processes is a constantly evolving field, what future can be expected for this cinematographic technique? The article ends with this open question and without providing an answer it implicitly states the role of stop-motion as a driving force for innovations that come from other fields and are incentivized by the needs of this specific sector.
\end{abstract}

Keywords: Stop-motion Animation, Puppets, Interdisciplinary Approach, Innovation Material Driven, Technology Transfers

\section{Introduction}

Stop-motion is an animation technique in which an object is physically manipulated and photographed on a single frame of motion picture film so that it appears to move on its own. The object is moved in small increments between individually photographed frames, creating the illusion of movement when the series of frames is played as a fast sequence (1).

The protagonist of this animation technique is the puppet.
Puppets are inanimate objects designed to tell stories through small movements and breaks that completely alter the dimension of time and create a gap between the time of the animator's work and that of the movement perceived by the public. These lifeless objects are manipulated by someone to create the illusion of life, and have a tangible presence and physical nature recognized by the audience, who are indeed enchanted. They move in an actual space, interacting with lights, gravity, and each other. And despite being created by the manual skillfulness of the puppet-maker, nothing about a 
puppet is accidental. From the shape to the movement, every phase of the development of a puppet is subjected to careful planning, long reflections and experiments, involving several professionals, aimed at solving different issues. A puppet is a design object that preserves a handicraft production process, and must, inevitably, pass out of the hands of skilled manipulators of matter, the puppet-makers, able designers.

There are several differences between the puppets used today by Aardman Animations studios and in Tim Burton's films, or in the models used by Willis O'Brian and Ray Harryhausen for their films. This suggests that the art of making puppets is full of technical and material variables, and consequently there are different meanings that these objects can communicate. Sometimes moldable materials, such as plasticine (used by Aardman studios and many other pioneers of Claymation) are used, other times toys with movable joints, or, more often, objects fitted with an internal armature, coated with semi-rigid materials (foam rubber or latex) that retain their shape without breaking as a result of twisting of the joints, are preferred.

Puppets are also an expression of style and a type of signature. In the most general analysis, as suggested by Ray Harryhausen and Tony Dalton, the puppets used by Aardman and Burton, and much earlier by George Pal for his Puppetoon series, are stylized human caricatures, whereas the models used by O'Brien and Harryhausen were interpretations of once-living mythical creatures and the aim was to convince viewers that they were watching real creatures in a real world [1].

\section{Attempts of Historical Systematization}

The history of stop-motion animation has been detailed and conveyed by several scholars and professionals who expressed different points of view and keys elements of the evolution of this animation technique in order to construct a more comprehensive one. In 2008, Director Ray Harryhausen published the most complete book about the last 120 years of puppet animation. It is a comprehensive and detailed analysis that, beginning from the trick devices invented by Méliès, arrives at the examples of "pure animation" developed by Tim Burton, Barry Purves, and Nick Park at the beginning of twenty-first century. Consciously partial descriptions of this evolution have been written by Bruce Holman, Adrián Encinas Salamanca, Ken Priebe and Neil Pettigrew. Holman, in the book Puppet animation in the cinema, intentionally concentrated on short and feature animated films: «for the purpose of this study we will only include those films in which the puppets are intended to be viewed as puppets» [2]. In addition, the book is not recent and the most recent films described therein were produced in 1975. Similar criteria of film selection have been used by the Spanish scholar Adrián Encinas Salamanca in the book Animando Lo Imposible. Los orígenes de la animación stop-motion (1899-1945). The book, the only one written in Spanish, is the most recent historical reconstruction of the evolution of stop-motion, but as the title suggests, it conveys a detailed and fully illustrated description (more than 600 figures) of the origins of this animation technique by the end of the Second World War [3].

Ken Priebe, in the recent book The Advanced Art of Stop-Motion Animation, published in 2010, explicitly clarifies the films that he wanted to focus on:

"I am referring to [...] films that fit into the following categories: A running time of anywhere from approximately 61 to 120 minutes; A theatrical release into festivals or cinema; the exclusive use of three-dimensional puppets, models, or clay figures throughout the entire film》 [4].

Pettigrew, on the other hand, in the introduction to the pair of volumes, The Stop-Motion Filmography, comments on the elaborate and surreal animated films produced by Starevicz, Blacton, Melboune-Cooper in the first decade of the twentieth century, arguing that «these films are historically interesting when tracing the development of stop-motion, but they fall outside the specific subject of this book» [5] that is, films in which puppets are supposed to be perceived as living beings. The last reference taken into account in order to trace a short panoramic view of the history and development of this animation technique is Stefano Bessoni's Stop-Motion. La fabbrica delle meraviglie. This is the only book written in Italian about the history of stop-motion, and describes the main events and protagonists (2).

\section{History of Materials and Fabrication Processes}

This section briefly explores the main phases and events of the development of this technique, following criteria based on the technological innovations that have influenced the fabrication of puppets until present day.

\subsection{Trick-Films and 'Toys Coming to Life'}

Stefano Bessoni places the history of the origin of stop-motion coincident with the beginning of cinema [6], when, at the end of the nineteenth century, the French film-pioneer Georges Méliès randomly discovered that «if the operator of one of the newly invented moving-picture cameras stopped turning the handle (the early cameras were all manually operated), paused, and then restarted, the result could be both intriguing and potentially useful» [1]. Méliès "trick-films" (3) mark the invention of the stop-motion replacement, however, according to Harryhausen, Méliès didn't see the potential of this discovery [1]. The first example of animation films using models, in particular toys, was created by British-born film-makers James Stuart Balckton and Albert Edward Smith, who in 1897 exploited what they saw in Méliès films as a new gimmick, and decided to try to film inanimate objects which were moved between frames to achieve the perception of movement. In 1897 they released the film considered the first to tell a story using animated three-dimensional objects: The Humpty Dumpty Circus (Figure 1), whose puppets are described by Harryhausen as wooden toy animals and acrobats belonging to Blackton's small daughter [1]. The first ten years of experimentation with 
this new shooting technique, not randomly, were characterized by stories about 'Toys coming to life', most likely because «toys (particularly ones with jointed limbs) made good actors and partly because the idea connected with a strong European literary tradition of stories about living toys» [7].

In this recurrent scenario some film titles are: Melbourne-Cooper's Matches: An Appeal (1899), The Enchanted Toymaker (1904), Noah's Ark (1906), Dreams of Toyland (1908), Cinderella (1912), Wooden Athletes (1912), The Toymaker's Dream (1913), Blackton and Smith's The Haunted Hotel (1907), Edwin S. Porter's The Teddy Bears (1907), Edward Rogers' War in Toyland (1912), Giovanni Pastrone's 1913 The War and The Dream of Momi [7].

From this moment, the history of puppets in cinema can be divided into the history of special effects, which makes terrifying creatures come alive and interact with real actors, defined "Dynamation" by Ray Harryhausen, and that of animated films. In both types of films puppets have always been the protagonists and the evolution of stop-motion is strictly related to the technique of fabrications and to the history of the materials used to build them.

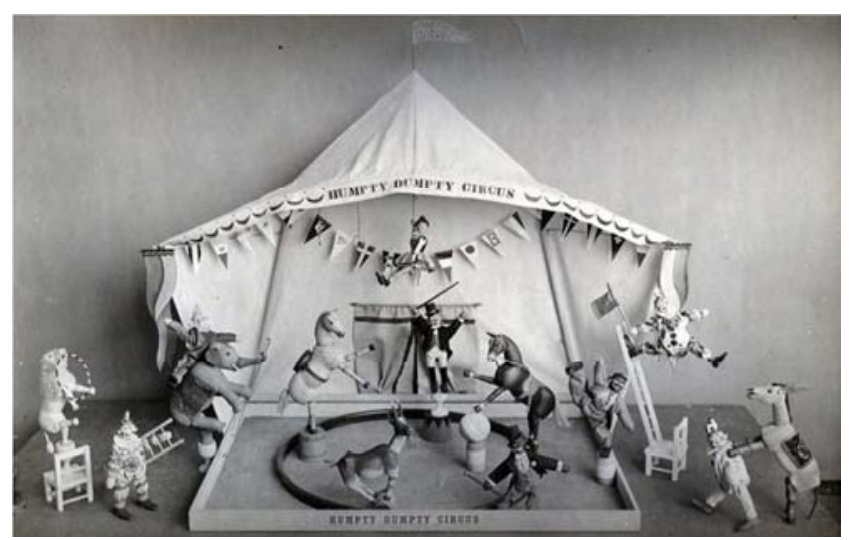

Figure 1. Humpty Dumpty Circus James Stuart Blackton, Albert Edward Smith (1897).

\subsection{Dead Beetles to "Build-up Puppets"}

The first puppets designed appositely to be filmed and manipulated in front of a camera, were fabricated by the Russian puppet animator Ladislaw Starevicz, who «used puppets that were generally "built up" from scratch, using many types of materials [...], including cotton, glass, cloth, wood, and balloons» [9].

Tom Brierton reveals that Starevicz, in the short The Mascot (1934), "fitted a wire armature within a real chicken skeleton and animated it walking and running» [9]. The first puppet film produced by Starevicz covering armatures with found materials (in particular insect exoskeletons) was Battle of the Stag Beetles (2010). These puppets consisted of real dead beetles, whose shells were preserved. The legs and mandibles, however, were removed and re-attached by sealing wax [7]. Starevicz made over thirty films between 1911-1918 using these materials (Figure 2). Meanwhile, he also developed the first examples of «models with steel ball-and-socket armatures padded out with sponge, which was then covered with light felt and leather» [1]. These original "build-up puppets" were technically implemented by Willis $O^{\prime}$ Brien. At the beginning of the second decade of twentieth century, O'Brien began experimenting with the possibilities of materials for this medium and designed the first puppets by «fashioning clothes and rubber over simple-jointed wooden skeletons» [5]. Using these, O'Brien produced a series of short films with prehistoric settings and creatures. Material experiments went on, and gradually the director obtained more and more realistic, light and flexible puppets.

"First, he replaced the wooden armature with a metal ball-and-socket skeleton. This new armature gave a model the flexibility he required while at the same tie allowing it to retain a position indefinitely. [Using] the cotton-wadding interior, he layered the outside of the model with sections of rubber, sealing the joints with a latex solution» [1].

O' Brien tried to improve this fabrication technique experimenting both with the armature, to improve the flexibility and quality of movement and with puppet's skin, with the aim of making it more realistic and detailed. Again Harryhausen explains that a relevant improvement was added by Marcel Delgado, who began working with O'Brien, introducing ball-and-socket armatures made of aluminum, which allowed for a smoother animation and better rigidity during the shooting, and suggested covering the outer area of the armature with sponge and cotton coated with liquid latex rubber, and finally painting the models [1]. The same method of modeling is largely still used today for the fabrication of puppets' bodies, with some more sophisticated and refined elements, following the techniques applied by O'Brien and Delgado for the first time in the fabrication of the giant gorilla in the 1933 King Kong [1].

In the book Stop-Motion Puppet Sculpting, Brierton defines the build-up technique «the precursor of foam injection», first applied by Marcel Delgado in the film Mighty Joe Young in 1949 [9]. According to Harryhausen, foam injection became the most common modeling technique applied to the design of animated puppets, because of the smoothness it produced in the puppets skin, and the easy reproduction of models potentially replaceable because they had exactly the same shape.

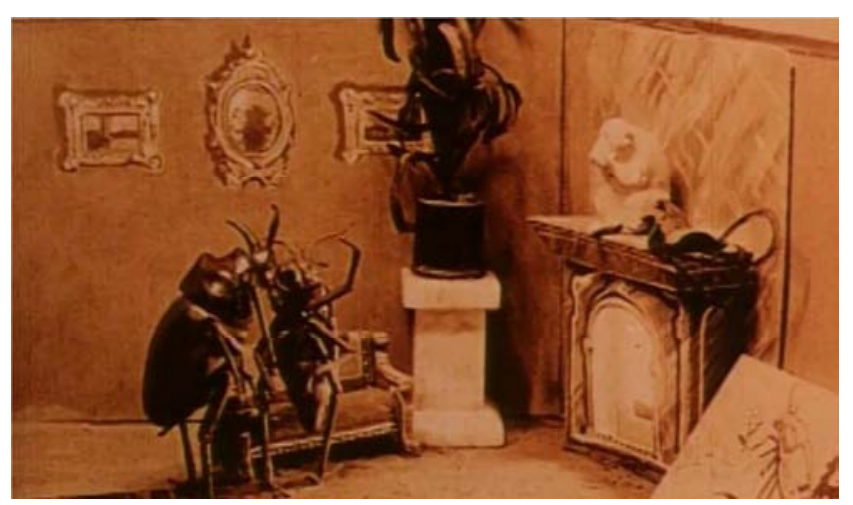

Figure 2. The Cameraman's Revenge - Ladislaw Starevicz (1912). 


\subsection{Clay and Plasticine}

In 1915, Willis O' Brien also made a one-minute film «featuring a miniature caveman and a model dinosaur made with clay, built around a wooden skeleton» [6]. Even though this was the only experiment in which O'Brien used clay, promptly substituted with sheet rubber, this experience signals an important step the in the path to making motion-picture cartoons with modeling clay. According to Michael Frierson, the cinematographic use of malleable plasticine was anticipated by the filmmakers George Fleming and Edwin Porter, who in 1902 produced the one-minute shot Fun in a Bakery Shop, considered a precursor to Claymation, that shows a baker sculpting a mass of bread dough into a series of faces, and filmed using the technique of stop-motion substitutions [10]. Both Harryhausen and Frierson identify the two American films, A Sculptor's Welsh Rarebit Dream, and The Sculptor's Nightmare, both released in 1908, as the earliest examples of clay animation. Unfortunately, there is no existing copy of the first one, but «both establish the narrative premise of a sculptor who [...] falls asleep and dreams of clay that magically builds itself into a finished bust» [10]. Wallace McCutcheon's The Sculptor's Nightmare, in fact, concerns a nightmare of a sculptor who sees himself creating clay busts of various American politicians that come alive during the night [1]. The appearance of modeling clay in the process of filmmaking proved extremely useful in the foam injection building technique, because the first prototype of the puppet, the maquette, used to build the mold is generally fabricated in plasticine [11].

Plasticine was the first synthetic modeling clay with the peculiar characteristic of malleability. Invented in Germany by Franz Kolb, who patented and sold it in 1880 , Kunst-Modellierton (artificial modeling clay) was subjected to involuntary revisions, and the product, as we know it today, was designed in the late 1800 by William Harbutt, Professor of Art in Bathampton (England), and Rector of Bath's School of Art and Design [9]. Harbutt was looking for a modeling paste that would make sculptures easier to make and would not harden when exposed to air. In 1897, a stroke of luck led to the creation of a non-toxic, soft, oily material that does not dry out, consisting of calcium salts, stearic acid, Vaseline, and colouring additives according to a recipe still protected by patent today [12]. In 1897 Harbutt published Harbutt's Plastic Method and The Use of Plasticine in the Arts of Writing, Drawing, and Modelling in Educational Work, and he soon realized the commercial potential of the invention, patenting it in 1899 with the name of plasticine [10].

Aside from a few short films using clay anthropomorphic figures, produced between 1910 and 1920, that we know very little about, clay animation was revived in 1955, when Arthur Clokey created Gumby «a flat, upended rectangle of greenishblue clay, divided at the bottom into two splayed, footless legs» (Figure 3). Gumby and the little red horse Pokey got an American institution for more then one decade [7].

Other animators adopted this puppet fabrication technique, which underwent a «renaissance in the 1960's [...] with the work of Peter Lord and Dave Sproxton [...] and the creation, in 1976, of Morph (Figure 4), the small terracotta man who interacted with the TV programme's artist Tony Hart» [7].

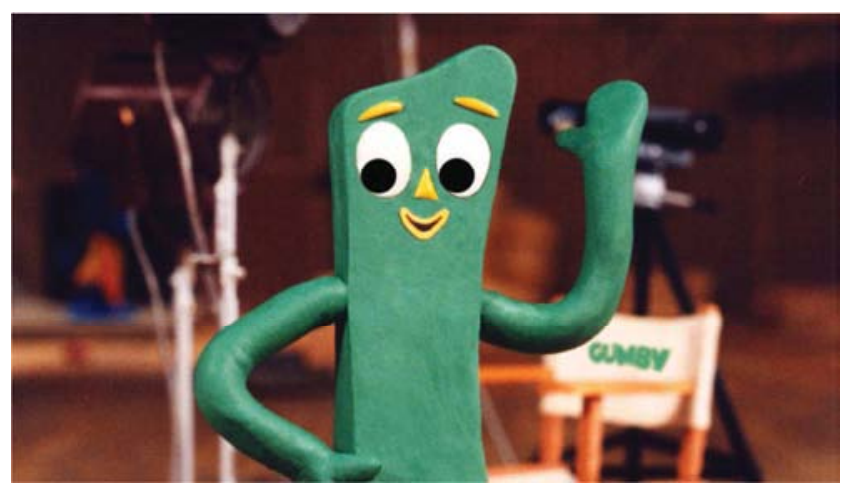

Figure 3. Art Clokey's green clay humanoid Gumby First appearance 1954.

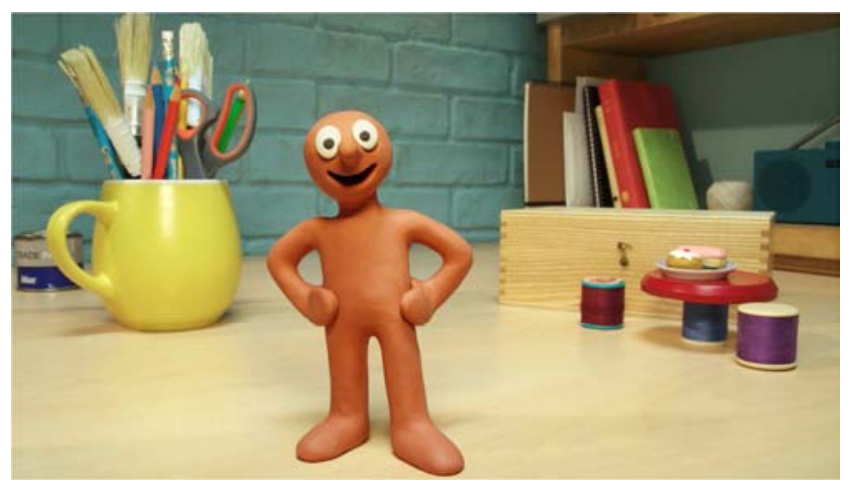

Figure 4. Preter Lord snd Dave Sproxton's clay character Morph First appearance 1977.

\subsection{Replacement Technique}

\subsubsection{Puppetoons}

In the 1930's in Germany, the Hungarian-born animator George Pal returned to the use of «animated toys» [2], and, by skipping the phase of armature fabrication and avoiding questions about the best material to use to obtain a realistic skin for the puppet, applied «the technique of substitution, a process having more in common with "cel animation" than with puppet animation» [13]. This technique has been around since the very beginning of the stop-motion medium, and Priebe identifies the earliest use of replacement faces in MoToy Comedias by American filmmaker Howard S. Moss in 1917 [4]. George Pal used this idea, and carved entire puppets switching them between the shooting of each frame, instead of adjusting and repositioning the initial puppet. Because of this, Pal needed to make a different puppet for each frame of the film (Figure 5). Pal's greatest short-film production took place when he moved to the US in 1939, where began producing a series of shorts called Puppetoons [7]. These replacement puppets were «very basic: heads and hands tended to be wooden balls, bodies were blocks of wood, and limbs were made of bendable covered wire» [7]. Stylistically these meticulously designed puppets remind of the "rubber hose" animation style popular in the 1920s, often seen in classic, hand-drawn animation such as Steamboat 
Willie (1928), in which «a character seemingly has no angular joints and displays loose, "rubbery" body movements». [8]

The replacement object technique evolved after Pal's Puppetoons, and several animators and directors began applying it to replace single parts of the entire puppet using different materials. Replacement pieces such as heads or mouths are still very common today. Although this technique is most widely used as a way of creating mouth plates, limbs, faces or entire heads, replacing the whole puppet is a method still applied also with the newest manufacture technologies of 3D printed replacement pieces that I will be discussing in the following section.

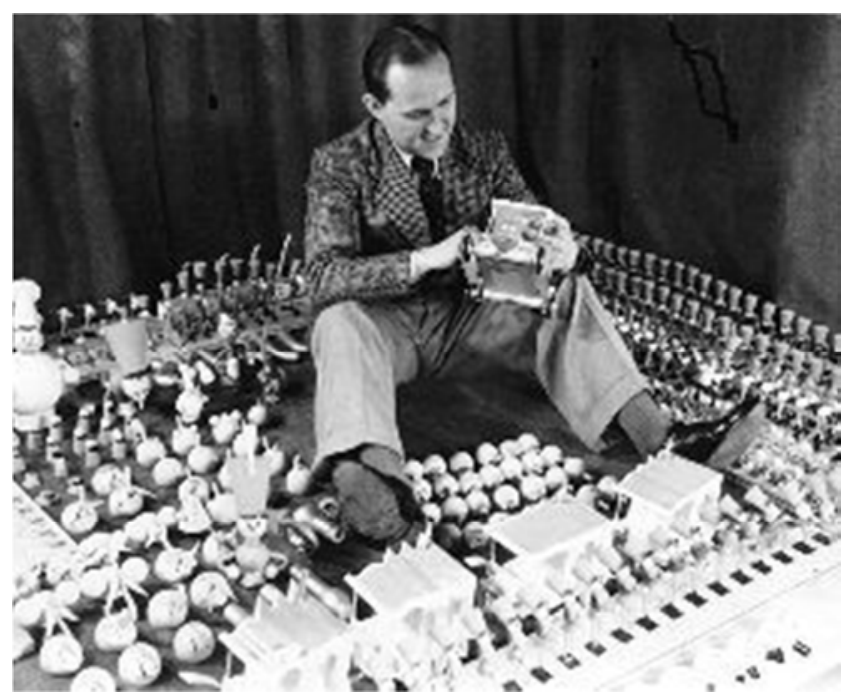

Figure 5. George Pal's Replacement Puppets.

\subsubsection{3: Tim Burton's "The Nightmare Before Christmas" and "Jurassic Park"}

The technique of replacement heads, together with the injection of foam to build the body, was used to fabricate puppets in the film that, in 1993, «changed the destiny of this technique» [6]: Henry Selick and Tim Burton's The Nightmare Before Christmas. The film was a real success, which allowed stop-motion to «get out of the darkness of wineries and attics of unknown independent filmmakers» [6], and travel to the conquest of Hollywood cinema, diffusing into cinemas all over the world. The film gave the technique a revolutionary cultural value; it is considered, in fact, the first important commercially produced films made entirely in stop-motion. This was the first feature puppet animation film produced by Disney. As Harryhausen states in his book, the film took nearly three years to make, and shows 74 puppet characters, represented by almost 300 puppets fully armatured with either wire-armature or wire/ball-and-socket combinations. Just for Jack, the main character (Figure 6), 150 interchangeable heads were used «to obtain the range of facial expression required» [1].

The Nightmare Before Christmas was nominated in 1993 for the American Academy Visual Effect award, but it was defeated by another film, Steven Spielberg's Jurassic Park, the film that changed «the world of special effects» [1]. With
Jurassic Park, cinema saw the demise of traditional model animation used to obtain special effects in Dynamation. Harryhausen relates that Spielberg involved Phil Tippett, one of the most expert animators in dinosaur movement and behavior, asking the director to supervise the dinosaur animation for the film. However, during this project Tippett Studios went through a transition from traditional animation to computer-generated animation [1]. 1993, therefore, marks a new era for puppet animated films and the end of stop motion as support for the special effects field.

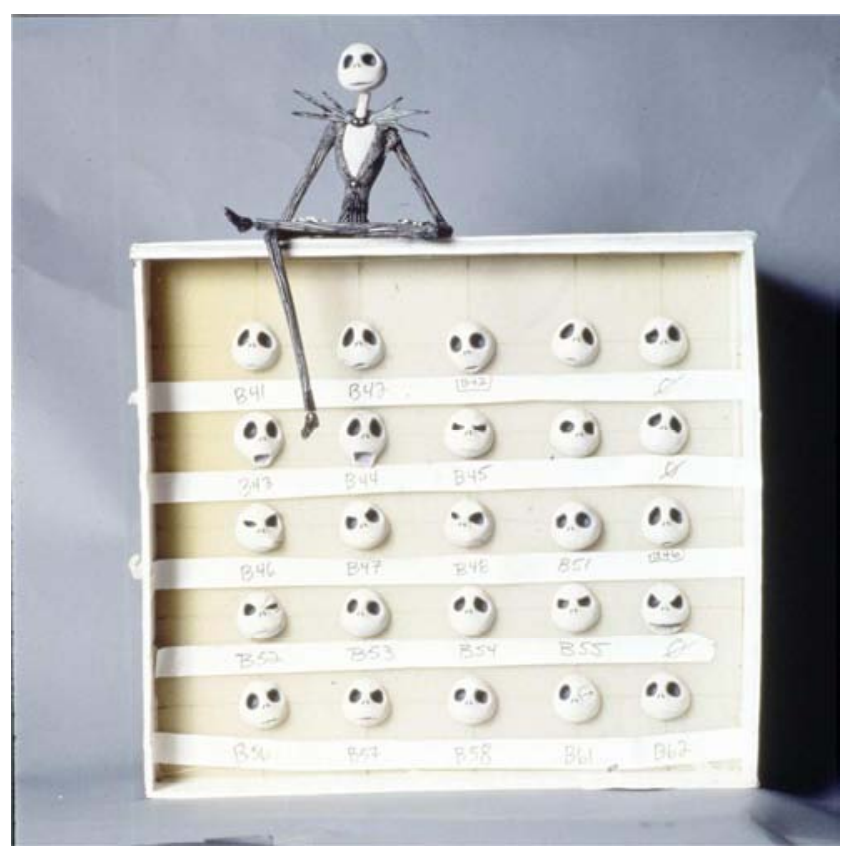

Figure 6. Jack Skellington's Replacement Faces Tim Burton's Nightmare Before Christmas (Henry Selick, 1993).

\subsection{The Technology of Puppets' Head's Fabrication}

Two relevant innovations in the technology of the fabrication and animation of puppets' heads happened in 2005's Tim Burton's Corpse Bride, and 2009's LAIKA's Coraline.

\subsubsection{Facial Animation in Tim Burton's "Corpse Bride"}

Based on a nineteenth century Russian-Jewish folktale, initially Corpse Bride was thought to have been made in CGI, but Burton «knew that the project would have much more resonance if it was done in stop-motion». The film, directed by Burton and Mike Johnson, who worked as animator on The Nightmare Before Christmas, had several breakthroughs [4]:

a. It was the first film to be shot in digital, by using a digital still-camera for the shooting of the entire film, a Canon EOS- 1D Mark II, that provided instant feedback of each scene;

b. It was the first puppet film to use Apple's Final Cut Pro;

c. The puppets, designed by leading English puppet manufacturers MacKinnon \& Saunders, were the first to employ a new technique for facial animation. Rather then using replacement heads, as had been done in The 
Nightmare Before Christmas, the Corpse Bride's puppets' faces were manipulated by complex mechanisms of paddles and gears underneath a silicone skin (figure 7).

"This involved building a complex gear system within the heads of the main characters to which "paddles" were attached. A soft, skin-like cladding, made of silicone and foam, was placed over the paddles to create the head and then painted. When the gears are operated by inserting an Allen key into small holes in the head or inside the ears, the paddles move, adjusting the facial expression of the character» [1].

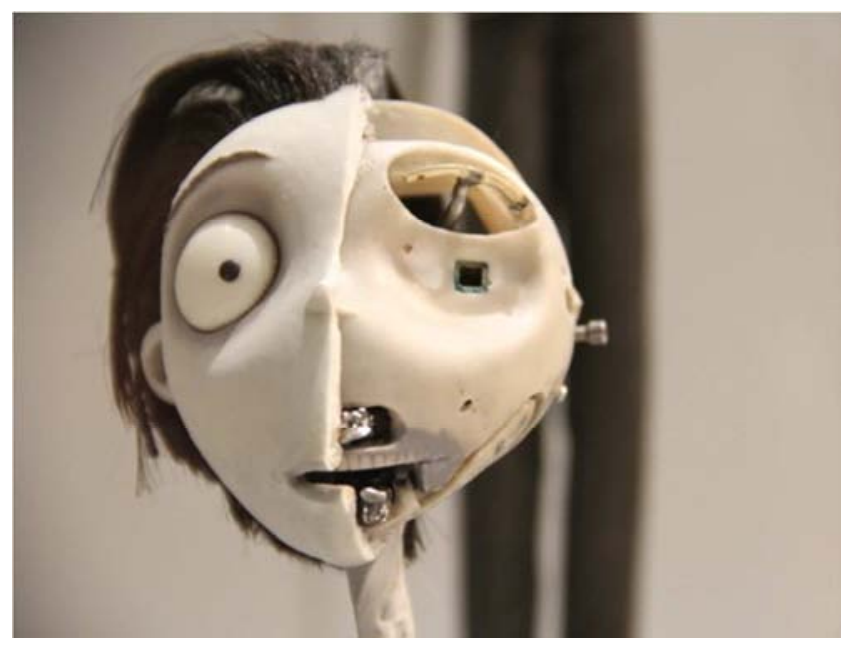

Figure 7. Victor Frankenstein's mechanical head Frankenweenie (Tim Burton, 2012).

\subsubsection{LAIKA's 3D Printed Replacement Faces}

2009 was an important year for stop-motion animation. Five full-length films were released: Adam Elliot's feature film Mary and Max, Wes Anderson's Fantastic Mr. Fox, the Belgian, French and Luxembourg co-produced stop-motion animated adventure A Town Called Panic, Jiří Barta's stop-motion animated Czech feature film Toys in the Attic, and Coraline, an American 3D dark fantasy stop-motion film based on Neil Gaiman's 2002 novel of the same name, written and directed by Henry Selick, and produced by LAIKA Studios in Portland, Oregon. Coraline was the first film to use two new technologies in stop-motion filmmaking:

-Stereoscopic photography, a new method «for shooting the stop-motion sets in 3D by taking left and right eye images of each frame and aligning them for stereo $3 \mathrm{D}$ projection» [4].

$-3 \mathrm{D}$ computer printed models of replacement pieces (faces and props) into physical resin materials. Ken Priebe accurately outline the process in the book The Advanced Art of Stop-Motion Animation, from the 2D sketches to the printing phase. He describe the phases in this order:

- 2D design and animation of lip-sync and changes of facial expression;

- sculpt of the clay maquettes of the key poses and scanning them into the computer;

- 3D generation of in-between positions and digital animation of the entire animated face sequences;

- export each individual frame of the face animation as an
STL (stereo-lithography) file and print out on a 3D printer;

Priebe describes these printers such as «a photocopy machine that prints liquid resin on a flatbed in layers». The process begins from the bottom of the model and is completed only when the top level of printed resin makes the pieces a hard replica of the model. This very long procedure allows one to obtain huge amounts of faces and facial expressions, all in perfect registration with each other (Figure $8)$. Sometimes the variety of expressions is implemented «by dividing the face into the upper and the lower halves, so that the mouth movements and lip sync could be combined with eyebrow movements in many different combinations», and then removing the seam between the two halves in post-production [4].

However, as Jed Alger points out, the $3 \mathrm{D}$ printers used in Coraline did not print in color, so every face needed to be hand-painted, and this operation had to be extremely precise to avoid the phenomenon that animators call chatter (if facial elements like freckles jump about the face from one frame to another). The same production company, LAIKA Entertainment, founded by Phil Knight in 2005, made a further step in 2012, with its second feature stop-motion film, ParaNorman, in which Brian McLean, LAIKA's Rapid Prototype department chief, incorporated a technology capable of embedding color directly into the printed faces (Figure 10).

"This new methodology - Alger argues - baked color into the material, obviating the need to hand paint each individual face and resulting in a face with a translucent quality similar to real skin, and a greater compatibility with the silicone in the puppet's bodies» [14].

Although Laika developed this innovative technique within the 2009 animation Coraline, various companies at the time simultaneously conceived this 'innovation', by applying a technology already established in the 1980s but only became available and reasonably affordable in the early 2000s [15].

Aardman, for instance, in 2012 released the feature film The Pirates! In an Adventure with Scientists, in which puppets had 3D printed replacement faces. High degree of visual realism both in the printed faces and in subtle movements within the animation itself was reached in Duke Johnson e Charlie Kaufman's 2015 animation Anomalisa. Along with these big productions numerous short films and commercials have been produced in the last decade using 3D printers to obtain replacement faces or bodies. Some titles are: Johnny Kelly's Het Klokhuis - The Apple Core (2010), Blue Zoo's Bear on stairs (2014), Raymond McCarthy Bergeron's short film Re-belief (2014), Gilles-Alexandre Deschaud's music video Chase Me (2015), Eran Amir's short film Run Baby Run (2016), Joris and Mariekes' short film Freeze (2015) and animated music video Happy Camper (2017), Montblanc's commercial The Magic of Craft (2016), and in the same year MacKinnon \& Saunders' commercial for British supermarket chain Sainsbury's The Greatest Gift (4).

$3 \mathrm{D}$ printing technology is clearly a useful tool for the development of replacement animation but relies upon the intervention of digital technologies as a relevant part of the manufacture process itself. 


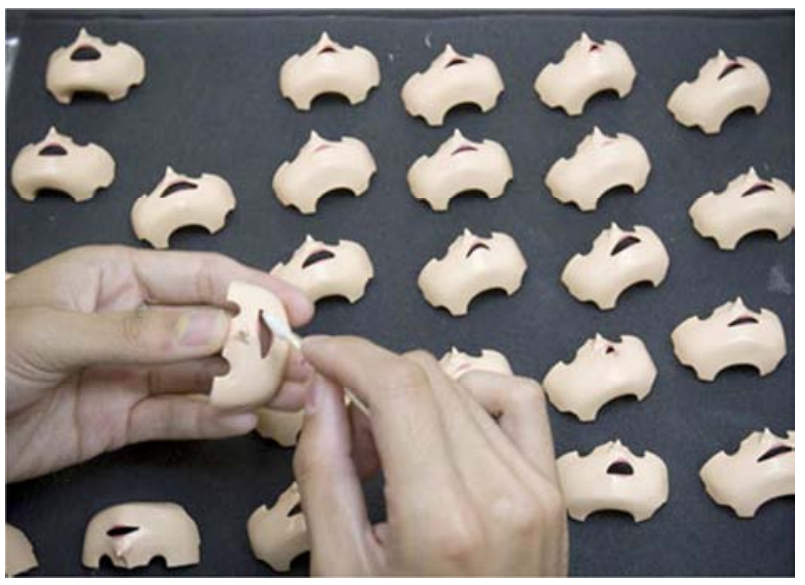

Figure 8. Coraline replacement $3 D$ printed puppet's faces Coraline (Henry Selick, 2009).

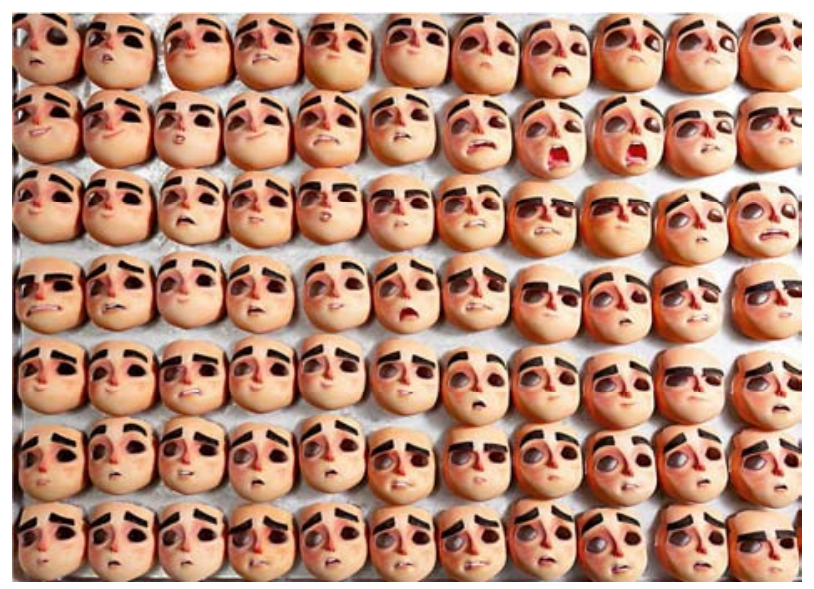

Figure 9. Norman replacement $3 D$ printed puppet's faces ParaNorman (Chris Butler, 2012).

\section{Stop-Motion and Computer-Generated Imagery (CGI)}

As demonstrated by the digital intervention in the process of realization of the $3 \mathrm{D}$ printed faces, stop-motion is increasingly influenced by innovative digital technologies and day after day they become more intrusive and less visible. The main examples of this intrusion are:

- the described digital modeling of character expressions, that are subsequently 3D printed and are replaced shoot after shoot to make puppets' expressions more authentic;

- stereoscopic photography;

- digital reconstruction or placing of the environment, that happens through different techniques: digital compositing with split-screen, masks, blue/green screen, and advanced post-production compositing of the background as in the short film Ava (5).

- digital editing of material details, adding or erasing puppets' skin's traces and texture, shadows, and rigging instruments;

- motion blur for replicating smooth movement of live action;

- parametric triangulation of the ranges of puppet's movements in digital workspace that simulate the real set in order to make the animated movement more real and as smooth as possible;

- the building of the digital environment embodying the same skills and proprieties from the physical workspace and that arouse the tactile, kinesthetic and proprioceptive senses in an haptic perspective [15].

- digital substitution of puppets' body details in postproduction phases.

An interesting case of the digital visual effects' supporting role in a stop-motion workspace is the digital substitution of puppets' body elements. This technique concerns the digital compositing of some puppets' elements with others shot in live-action videos and then placed on the animated frames. Two examples of compositing of real human eyes onto the face of the puppets are Chris Lavis and Maciek Szczerbowski's Madame Tutli-Putli (2007), and Johan Oettinger's Seven Minutes in the Warsaw Ghetto (2012).

\subsection{Chris Lavis and Maciek Szczerbowski's “Madame Tutli-Putli"}

The first example is the 2007 Academy Award-nominated short film Madame Tutli-Putli, directed by Chris Lavis and Maciek Szczerbowski for the National Film Board of Canada. The film tells the story of a young woman who takes a thrilling journey aboard a train at night. As mentioned, characters' eyes are actually «made up of video footage of real human eyes, which were painstakingly composited onto the faces of the puppets» [4]. The film has been the first case of this form of hybridization in which stop-motion dialogues with live-action through the digital manipulation and overlapping of the two form of video-making. This technique then is a digital alteration and hybridization of two video techniques reported to their compositional grammar: a sequence of consecutive frames. As Priebe writes in his book: «Seeing human eyes on a stop-motion puppet in Madame Tutli-Putli is something we've never seen before, and the effect of the film comes down to the fact that it looks like the eyes are there» [4].

The director Jason Walker, in an interview conducted by Priebe, details the phases of the long process of this technique and reveals that in order to provide a demonstration of the effective feasibility of this intuition and make the new technique work, the process requires three basic steps:

- film the actress (Laurie Maher);

- track the puppet;

- stabilize the footage of the eyes to stick onto the puppet face (Figure 10).

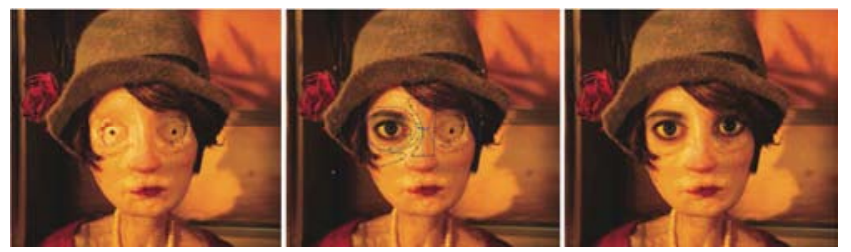

Figure 10. A progression of steps showing the puppet's tracking markers, masks, and composited eyes. Madame Tutli-Putli (2007). 


\subsection{Johan Oettinger's “Seven Minutes in the Warsaw Ghetto"}

The same technique has been successfully applied in the 2012 animated puppet short film Seven Minutes in the Warsaw Ghetto, directed by Johan Oettinger. The films narrates the vicissitude of Samek, an 8-year old Jewish boy living in the Warsaw Ghetto with his family during the $2^{\text {nd }}$ World War, who one day peeks through a hole in the ghetto wall and sees a carrot lying on the sidewalk just on the other side. He tries to pull the carrot through the hole with a piece of wire, unaware that two SS men are following his every move. Oettinger wanted real eyes from actors to be composited onto the puppets to emphasize facial expressions and emotions. As in previously described Madame Tutli Putli this was done by «shooting close-ups of the actors' faces while playing out the scene and then isolating only the eyes and eyebrows» [16], and then composing them onto the faces of the puppets.

A relevant aspect of this technique is its effective manual control. During the above mentioned interview, repeatedly Walker emphasized the manual work still required by this technology that consists of «position[ing] a human eye one frame at a time onto the head» [4], and provides a very simple and romantic justification to the fact that only the brain can verify if the composed footages work properly. The director says: "Your computer is not going to understand human emotion - only your brain can do that» [4].

\section{Other Material Experiments}

Stop-motion animation evolution's history counts also numerous material experiments, which saw animators and puppeteers challenging the possibility of material performances. Many of them were isolated experiments that were never followed. Nicolae Sfectu, in the book The Art of Movies (2014), mentions a technique used by the Oscar-Winning animator Will Vinton (The founder of the term "Claymation") in 1974, and calls it "clay melting". This sub-variation of clay animation exploits the susceptibility of plasticine to melting in high temperatures [17]. There are few but relevant examples that use this cinematic technique, for example in the final scene of the 1974 short film Closed Monday, directed by Will Vinton and Bob Gardiner, when the computer melts in front of the protagonist, or in the final scene of Indiana Jones and the Raiders of the Lost Ark, directed by Steven Spielberg in 1981 [17]. Another experiment was conducted in 1949 by the Czech animator Karel Zeman. In the short film Inspirace (Inspiration) (Figure 12), Zeman fabricated «all characters or figurines [...] of glass and animated by heating them after each frame was shot to allow them to be moved» [1]. This was an extremely long process and this is likely the reason why, as Harryhausen suggests, no one else, not even Zeman, used it again.

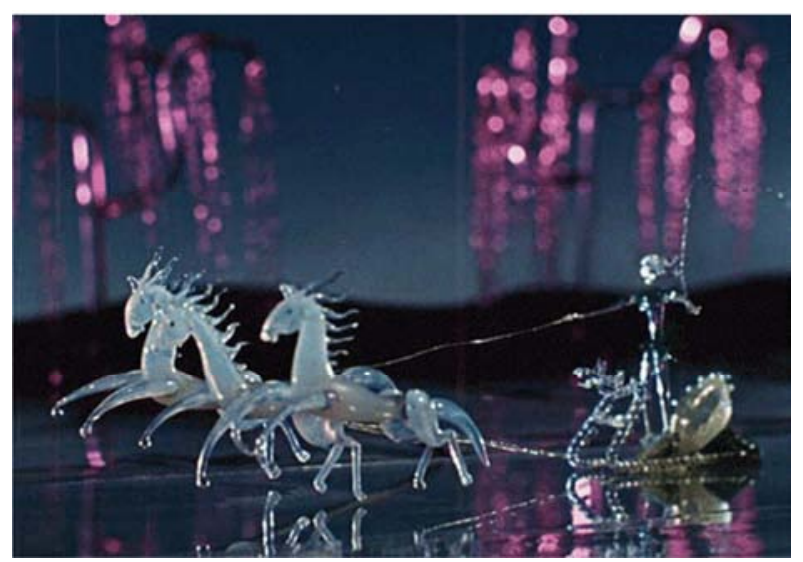

Figure 12. Inspirace, Karel Zeman (1949).

\section{Conclusion}

This short and partial history of stop-motion animation aim at demonstrating the strict relation between material experiments, technological innovation and the evolution of this cinematographic technique. By crossing the two fields of material design and puppet animation, both the evolution of material technologies as a driver of innovation in the technology of puppets fabrication, and the stylistic or narrative needs of animators and puppet makers that accelerated and defined new paths of development of technologies and processes borrowed from other fields have been illustrated. Technology transfers and innovations potentially applicable are numerous and many paths are still un-explored. This animation technique based on craftsmanship and manual ability, therefore, is still full of challenges and hypothesis of evolution.

In 1975 Holman placed a question about directions and challenges puppet animation will have likely taken in the future. After almost half century this question is still relevant and alongside with the numerous innovations developed, stop-motion's potential is far from being fully discovered and it seems to take more and more advantages of new technologies. But, how much remains of the artisanal purity of this technique with the increasing application of digital technologies? The aim of this article is not to focus on interaction between stop-motion and digital technologies, and the author doesn't want to provide any personal opinions about the digital alteration of the artisan nature of the medium. Hybrid productions exist and they are not just changing the quality of the movement and the appearance of puppets, but the balance between realism and fiction, and stop-motion is increasingly acquiring the power to blur this line.

\section{Notes}

a. The short description has been developed taking into account the definitions provided by following books: L. B. Holman (1975), Puppet animation in the cinema. History and technique, 11; S. Shaw (2004), Stop Motion. Craft skills for Model Animation, 1-4; K. A. Priebe (2006), The Art of Stop-motion animation, 129; S. 
Bessoni (2014), Stop-motion. La fabbrica delle meraviglie, 8; B. JC Purves (2014), Stop-motion Animation: Frame by Frame Film-making with Puppets and Models, 9-13.

b. Bessoni's book is a short compendium about the history of the technique. Published in 2014 it is the most recent version of the historiographical analysis considered in this article.

c. The names "trick-film" and "stop-and-start films," have been coined by Arthur Melbourne-Cooper at the beginning of $\mathrm{XX}$ century to define his creations [Harryhausen, Dalton, 2008: 40].

d. Mentioned titles were listed by Laura-Beth Cowley's in the SAS 2018 conference paper The changing face of Replacement Animation: How looking to the past can revolutionise the future of Stop-Motion Animation.

e. The complex process has been explained by the director Henrique Moser in an interview conducted by Ken Priebe and reported in the book The Advanced Art of Stop-motion Animation (2010), pp. 260-262.

\section{References}

[1] Harryhausen, R. \& Dalton, T. (2008), A Century of Stop-Motion Animation: From Melies to Aardman. New York: Watson-Guptill Publications, pp. 21- 73, 165, 204-223.

[2] Holman, L. B. (1975), Puppet animation in the cinema. History and technique. New York: A. S. Barnes, pp. 12-56.

[3] Salamanca, A. E. (2017), Animando Lo Imposible. Los orígenes de la animación stop-motion (1899-1945). Madrid: Diabolo Ediciones.

[4] Priebe, K. A. (2010), The Advanced Art of Stop-Motion Animation. Clifton Park: Cengage Learning Inc, pp. 4-57, 139-142, 272-276.

[5] Pettigrew, N. (1999), The stop-motion filmography. A critical guide to 297 features using puppet animation, Vol 1. Jefferson: McFarland \& Company Inc. Publishers, p. 10.

[6] Bessoni, S. (2014), Stop-motion. La fabbrica delle meraviglie. Modena: Logos Ed, pp. 8-16.

[7] Lord, P. \& Sibley, B. (2015), Cracking animation: The Aardman book of $3 D$ animation. London: Thames \& Hudson Ltd, pp. 25-53.

[8] Furniss, M. (2017). Animation the Global History. London: Thames \& Hudson, p. 48.

[9] Brierton, T. (2004), Stop-Motion Puppet sculpting. A manual of Foam Injection, Build-Up and Finishing Techniques, Jefferson. North Carolina, and London: McFarland \& Company Inc. Publishers, pp. 1-47.

[10] Freirson, M. (1994), Clay animation. New York: Twayne Publishers, pp. 31- 43.

[11] Shaw, S. (2004), Stop motion: craft skills for model animation. London: Focal Press, p. 77.

[12] Polo, E. (2008), Mi piego, ma non mi spezzo! Plastilina, Pongo ${ }^{\circledR}$ e paste per modellare. In: AIM magazine. Ferrara: Pacini Editore, p. 27.

[13] Shires, J. (2001), Careers in computer animation, New York: The Rosen publishing group Inc., p. 50.

[14] Alger, J. (2012), The Art and Making of Para Norman. San Francisco: Chronicle books, pp. 50.

[15] Goldberg, D. (2018) History of 3D printing: It's older Than You Are (that is if you're under 30). Retrieved from https://www.autodesk.com/redshift/history-of-3d-printing/

[16] Dima, M. (2013), A design-led approach for transferring the embodied skills of puppet stop-motion animators into haptic workspaces, $\mathrm{PhD}$ thesis, Edinburgh College of Art.

[17] N. a. Eye Compositing Videos from Seven Minutes in the Warsaw Ghetto. Retrieved from https://itsoncraft.com/eye-co mpositing-videos-from-seven-minutes-in-the-warsaw-ghetto/

[18] Sfetcu, N. (2014), The Art of movies, ebook. 